\title{
Additive Manufacturing in Healthcare
}

\author{
Marisela Rodríguez-Salvador \\ Professor,marisrod@itesm.mx
}

\section{Leonardo Azael Garcia-Garcia}

Postdoctoral Fellow, leonardogarcia@itesm.mx

\begin{abstract}
Escuela de Ingeniería y Ciencias, Tecnológico de Monterrey, Avenida Eugenio Garza Sada 2501 Sur, Colonia
Tecnológico, Monterrey, Nuevo León, 64849, México
\end{abstract}

\begin{abstract}
$\mathrm{T}$

he presence of additive manufacturing (AM), in particular $3 \mathrm{D}$ printing, is relatively young, but dynamic field that is changing the face of many sectors. Additive production technologies provide wide opportunities for the creation of complex and personalized products and the reduction of time, labor, and other expenses. This paper will focus on AM in healthcare and identify the main areas for its application and the most popular materials. The period under analysis is from January 2005 to April 2015. The analysis involved an iterative search to establish the best queries for retrieving data and a patent

analysis. The obtained results were assessed by experts in the field. Through this research, three main applications were identified with dental prosthetics being the most prolific. A wide range of materials were identified, where plastics predominate. Polyethylene was most frequently patented for vascular grafts and tendon replacements, while ceramics were found to be the most useful material for dental applications. Only a few patents disclosed the use of metals, titanium being the most prevalent. This research provides valuable insights for the advancement of additive manufacturing in healthcare applications.
\end{abstract}

Keywords: 3D printing; additive manufacturing; materials; healthcare; dental; vascular graft; patent analysis.

Article type: research paper
Citation: Rodríguez-Salvador M., Garcia-Garcia L.A. (2018) Additive Manufacturing in Healthcare. Foresight and STI Governance, vol. 12, no 1, pp. 47-55. DOI: 10.17323/2500-2597.2018.1.47.55 
$\mathrm{E}$ ffective strategy planning for research and development (R\&D) is impossible without an understanding of the emerging scientific and technological landscape and the latest breakthroughs. Over the last several years efforts have been devoted to assessing the evolution of technology through an analysis of scientific publications and patents. This research incorporates a competitive technology intelligence (CTI) method through patent analysis and is complemented by an expert assessment.

Competitive technology intelligence is the systematic process of gathering and analyzing information to support strategic planning for innovation. Among other tools CTI utilizes patent analysis as an indicator of technological growth, to identify advances in processes, new materials, and the more active players. Patenting is considered one of the key ways of protecting intellectual property [Okamoto et al., 2017; Zhang et al., 2015], which provide unparalleled value for business, law, industry and policy-making communities. These documents are organized, classified, and processed in such a way that provides information such as inventor's name, owner, claims, etc. Patents can also be used to monitor technology trajectories [Bonino et al., 2010]. Economic indicators have been also associated with patents, for example they help address connections between technology and trade [Archibugi, Pianta, 1996] and help elucidate the strong relationship between the activity of an industry and the pattern of industrial specialization. The growth of industries is influenced by technology, and this is better understood through an analysis of the industries' innovative activities and national performance [Fabry et al., 2006; Rodríguez et al., 2014]. Patent analysis has established itself as a great platform for knowledge discovery [Bonino et al., 2010; Archibugi, Pianta, 1996; Fabry et al., 2006; Rodríguez et al., 2014; Abercrombie et al., 2012]. For example, Trappey et al. [Trappey et al., 2015] consider patent analysis the major method for predicting new technologies.

Patent analysis can serve as a landscape of the developing technological areas. It represents an important tool for understanding the dynamics of scientific and technological advances, furthermore it has been used since the early 1970s in the US [Attar, Fraenkel, 1977]. Currently, it can be used to predict competitors' possible future moves. However, the objectives and final applications depend upon the project in question [Fujii, 2007]. For example, previous studies include: the identification of past trends and the predicting of future trends using clusterization and time series of patent data [Chang et al., 2014], the identification of indicators to determine technological investments and markets strategies [Dehghani, Dangelico, 2017], and the determination of a technology's diffusion rate, lifecycle, patent expansion potential, and patent power [Altuntas et al., 2015]. Whichever objective is pursued, patent analysis is a highly demanding task that requires a significant degree of expertise on the technological domain to be studied. In this research, expert feedback has been incorporated into the competitive technology intelligence (CTI) analysis in order to obtain the best approach for identifying the use of additive manufacturing in medical applications and their most used materials.

The manufacturing of medical devices has undergone a radical change with the incursion of AM, a relatively new technology that generates products by "printing" layers of materials using a cartesian coordinate robot, as does an ink or laser printer, to deposit or fuse material layer by layer to generate objects in three dimensions. This process can be performed using different techniques, such as selective laser sintering (SLS), thermal inkjet printing, or fused deposition modeling (FDM), among others. These technologies are more common now, with new methods and materials being employed, as well as new applications where the advantages of this technology can be used [Ventola, 2014; Schubert et al., 2014]. This technology has a huge impact upon various industries, due to advantages such as the creation of complex shapes, personalized final products (such as implants) as well as a reduction in time and waste.

$\mathrm{AM}$ is in fact a promising technology that will revolutionize the healthcare industry, as it provides the opportunity to create custom tools and equipment, as well as tailored medical devices, such as implants [Ventola, 2014]. By means of this technology, implant manufacturing time can be dramatically reduced in comparison with traditional methods that involve several processes [Ventola, 2014; Hornick, 2016]. Moreover, implants can also be generated on the basis of a patient's personal anatomy, thus securing a better fit and reducing the probability of failure common for mass-manufactured implants. For example, to create a prosthesis, the patient's images are obtained by X-ray, a computerized tomography (CT) scan, or magnetic resonance imaging (MRI). A 3D model is generated afterwards and transformed into a 3D print file that is used subsequently to build the necessary part. A similar process has been successfully used to generate cranial, jaw, or pelvic implants, as well as prostheses for the upper and lower limbs [Hornick, 2016]. These products involve biocompatible materials such as titanium or stainless steel [Ventola, 2014; Schubert et al., 2014; Hornick, 2016; Banks, 2013; Álvarez, Nakajima, 2009].

AM technology has evolved rapidly and has made a huge impact upon patent applications. In 2014, the growth of AM was accelerated, increasing by $31.6 \%$ from 2013 to 2014, and 25.9\% in 2015 [Wohlers et al., 2016]. Photopolymers were the most used materials in AM by 2016, being used in $45.5 \%$ of the 
applications, followed by laser sintering polymer powders $24.9 \%$, filaments $15.1 \%$, and metals only comprising $11.5 \%$. Such developments are increasing patent activity in the AM industry with continuous growth from 25 issued patents in 1995 to 668 in 2014 [Wohlers et al., 2016]. In the medical sector, intellectual property has grown relatively rapidly since 2009 , being dominated by companies more than academic institutions. In 2014, the AM industry was worth $\$ 700$ million, and just $1.6 \%$ was invested in the healthcare industry, meanwhile, by 2024 it is expected to grow to $21 \%$ [Schubert et al., 2014]. As this industry continues growing and expectations rise, it is important to track its evolution. Global efforts have been carried out to identify the technologies and applications of AM in the healthcare sector. Recently, Ventola [Ventola, 2014] studied the advances and benefits of AM, identifying some future trends. On the other hand, Schubert et al. [Schubert et al., 2014] offered an overview of AM in the healthcare sector and identified potential applications and expected economic growth in this sector. Rodriguez et al. [Rodriguez et al., 2014] presented a patent analysis to identify global trends in biological AM, by determining countries, organizations, inventors, and technological fields. Materials and processes in AM are evolving continuously and constitute a great opportunity to innovate and make decisions to become more competitive. However, patent analysis to track their presence has not yet been developed. To fill this gap, this research presents a patent analysis enhanced by an expert assessment to uncover opportunities for research and innovation on the materials used in AM for medical applications.

\section{Research Methodology}

As this research involves two areas, AM and the healthcare industry, the collection of data turns into a more difficult task. A customized search strategy is required to overcome this difficulty, and a set of queries must encompass the appropriate information for the analysis. If a query is poorly defined, it will result in a shortage of relevant information. Queries were defined first for a ten-year period, 2005-2015, up to April 15, when the study was concluded. The main applications and the most used materials are disclosed in this paper as well as the number of patents per year. This can provide insights and a better understanding of advances in the field of additive manufacturing.

Globally, the methodology presented here involves several steps: 1) the planning process, 2) the identification of sources of information, 3) the development of a strategy for information collection, 4) data collection, 5) expert validation, 6) data analysis, 7) experts' validation of the analysis, and 8) the delivery of results. This is done as an iterative process until results are validated and delivered.

The planning process (Step 1) includes the definition of the main goals and activities, including the allocation of resources to identify the materials for and applications of AM in the healthcare sector. The next stage (Step 2) included the identification of the sources of information. For this step, a comprehensive source of information was selected to track the registered inventions, PATSEER ${ }^{1}$, which is a powerful web-based platform covering more than 92 million records from the main patent authorities worldwide. It has access to bibliographic data from 140 countries and full texts from 27 authorities ${ }^{2}$. The next step (Step 3) involved the definition of keywords and the generation of the most suitable search queries. This step was completed by performing an extensive analysis of papers and reports from scientific databases combined with expert consultations in order to define a set of keywords to retrieve information. This process was carried out in a recursive way, by modifying the search queries as described below. The step that follows (Step 4) involves the collection of information, where documents were selected by analyzing the titles and abstracts. This step was followed by an expert assessment (Step 5) to determine whether the results were suitable for carrying out the analysis. Data analysis is the next step (Step 6), and this was accomplished with the help of a text mining software, Patent iNSIGHT Pro ${ }^{3}$, which is a patent analysis tool that uses advanced algorithms. This software includes sophisticated analytical capacity tools to analyze thousands of documents, thus obtaining an insight into the scientific field. During this step, the results were analyzed and cleaned up to eliminate noise, which are patents that could be retrieved but do not relate to the topic of interest. After cleaning out irrelevant patents, the results were assessed by experts, enhancing the validation process and determining the eligibility of the information (Step 7) to develop the analysis and then, finally, to deliver results (Step 8), which include the identification of opportunities to innovate and any possible threats to success.

\footnotetext{
Available at: https://patseer.com/, accessed 15.11.2017.

${ }^{2}$ European Patent Office, World Intellectual Property Organization (WIPO), as well as national patent offices of United States, Japan, China, Republic of Korea (South Korea), Canada, Germany, France, Great Britain, Spain, Australia, India, Switzerland, Austria, Brazil, Thailand, Russian Federation, Philippines, Sweden, Norway, Denmark, Finland, Belgium, Netherlands, Luxembourg, and Mexico.

${ }^{3}$ Available at: https://www.patentinsightpro.com/, accessed 15.11.2015.
} 
Table 1. First patent search

\begin{tabular}{|c|c|c|c|}
\hline Query & Title + Abstract & Title + Abstract + Claim & Patents \\
\hline Additive manufacturing & x & - & 960 \\
\hline Additive manufacturing & - & X & 1558 \\
\hline Additive manufacturing AND Medical devices & - & X & 17 \\
\hline $\begin{array}{l}\text { Additive manufacturing AND (Medical devices OR Prostheses } \\
\text { OR Orthoses) }\end{array}$ & - & X & 41 \\
\hline $\begin{array}{l}\text { (Additive manufacturing OR 3D printing) AND (Medical } \\
\text { devices OR Prostheses OR Orthoses) }\end{array}$ & - & X & 86 \\
\hline
\end{tabular}

During the initial process, the most crucial tasks included the definition of keywords and the construction of the search query, which is needed for the proper identification of information that feeds the scientometric analysis. The queries were built using a Boolean search.

After the keywords are determined in Step 3, new complementary terms were added in the search strategy as follows: given a specific term in a given period of time, the search was defined by the abstract, title, and claim, as described in Table 1, then the results were analyzed. The term was eliminated if the results did not fit within the framework of the research and a new term was tested. The algorithm of queries' modification is summarized in Table 2 .

The initial timeframe (at the Stage A) was defined as the period from 1700-01-01 until 2015-04-15, the first being the oldest date for the time frame that can be obtained from the platform, 1700-01-01, up to the most recent date, when this research was concluded, 2015-04-15.

\section{Table 2. Algorithm for Modifying Search Queries}

\begin{tabular}{|c|c|c|}
\hline \begin{tabular}{l|}
$\begin{array}{l}\text { Number } \\
\text { of query }\end{array}$ \\
\end{tabular} & Fields & Query formulation \\
\hline \multicolumn{3}{|c|}{ Stage A. Initial set of search queries (publication date: 1700-01-01 to 2015-04-15) } \\
\hline 1 & Title, abstract and claims & additive manufacturing \\
\hline 2 & Title and abstract & additive manufacturing \\
\hline 3 & Title, abstract and claims & additive manufacturing AND medical devices \\
\hline 4 & Title, abstract and claims & additive manufacturing AND (medical devices OR prosthesis OR orthosis) \\
\hline 5 & Title, abstract and claims & (additive manufacturing OR 3D printing) AND (medical devices OR prosthesis OR orthosis) \\
\hline \multicolumn{3}{|c|}{ Stage B. Search during a 10-year period (publication date: 2005-01-01 to 2015-04-15) } \\
\hline 6 & Title and abstract & $\begin{array}{l}\left.\text { (additive manuf }{ }^{\star}\right) \text { OR (3D manuf }{ }^{\star} \text { OR 3-dimension* OR } 3 \text { dimension }{ }^{\star} \text { ) OR (3D print }{ }^{\star} \text { OR } \\
\text { 3-D print }{ }^{\star} \text { OR } 3 \text { print }^{\star} \text { ) }\end{array}$ \\
\hline 7 & Title and abstract & 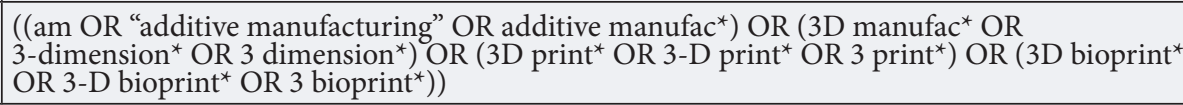 \\
\hline 8 & Title and abstract & 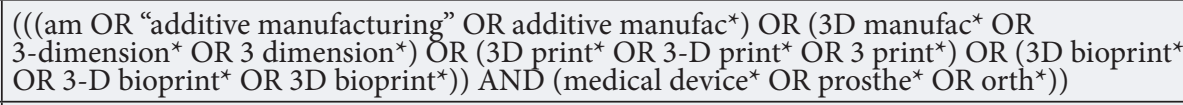 \\
\hline 9 & Title and abstract & 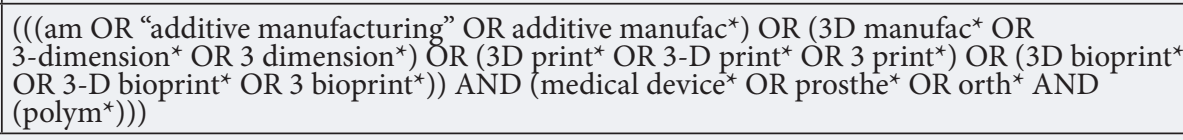 \\
\hline \multicolumn{3}{|c|}{ Stage C. Search with material term combinations (publication date: 2005-01-01 to 2015-04-15) } \\
\hline 10 & Title and abstract & 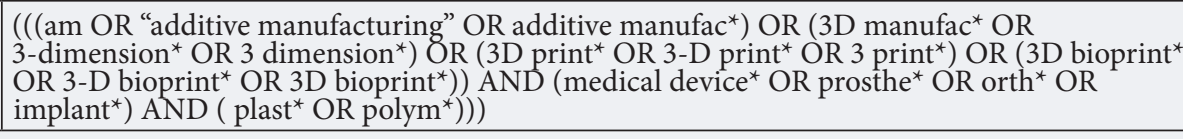 \\
\hline \multicolumn{3}{|r|}{ Stage D. Final Search (publication date: 2005-01-01 to 2015-04-15) } \\
\hline 11 & Title, abstract and claims & 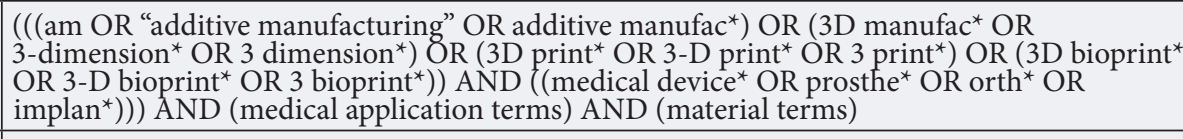 \\
\hline 12 & Title, abstract and claims & 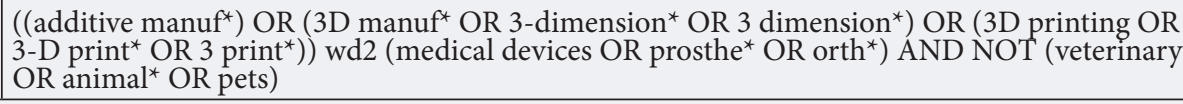 \\
\hline
\end{tabular}


- Acrylonitrile Butadiene Styrene (ABS) Plastic

- Alkyd

- Aluminum

- Carbon Fiber

- Clay

- Elastomers

- Epoxy

- Fiberglas

- Furan

- High-density Polyethylene

- Melamine

- Methacrylic

- Nickel
- Nylon

- Polyether Ether Ketone (PEEK)

- Palladium

- Phenolic

- Plastic

- Polyparaphenyleneterephtalamide

- Polyamide

- Polyamideimide

- Polycarbonate

- Polyetherimide

- Polyethylene

- Polyethylene Terephthalate

- Polylactic Acid

- Polyolefin
- Polyphenylsulfone

- Polypropylene

- Polyvinyl Chloride

- Polyvinylidene Chloride

- Room-Temperature-Vulcanizing (RTV) Silicone

- Rubber

- Silver

- Stainless Steel

- Steel

- Thermoplastic

- Thermoset

- Titanium

Source: composed by the authors.

From the searches carried out using the Queries 1 to 5, it was found that the keywords listed above are indexed with different terms on the patents, which were used to comprise all the denominations related to 3D printing technology. The Boolean operators: OR, AND, and NOT were also used, as well as the asterisk $\left.{ }^{*}\right)$ to encompass all words with the same root but different ending. We describe how to complete the search in the following paragraphs.

According to the feedback from experts, it was determined that the main inventions were developed from 2005 onwards, so at the Stage B the timeframe was established for ten years and the search parameters for the stage B were adjusted as shown for Query 6 in the Table 2.

A technological level search (additive manufacturing) was developed using the parameters described for Query 7 in the Table 2.

The next step was made in order to narrow the results to only medical application terms according to Queries 8-9 (see Table 2).

Stage C was focused on finding material combinations. Query 10 in Table 2 shows an example of the strings generated, a string built with the terms for plast* and polym*.

Finally, at Stage D approximately 200 searches were carried out in order to identify the use of additive manufacturing for inventions dealing with different parts of the human body and materials involved. Box 1 lists the material terminology used to collect patent information. Forty materials were identified, each one was combined with the different medical application terms. After this search, the main applications were identified from the patent analysis combined with the expert assessment. The obtained insights showed that the largest amount of patent activity in this field was focused on dental, vascular graft, and tendon applications, thus, a specific analysis was developed for each using the following search strings (query 11, see Table 2).

\section{Results}

In total, 1,558 patents were obtained using the search string with "additive manufacturing" in the abstract, title, or claim during the period from 1700-01-01 to 2015-04-15. The number of results was further reduced to 960 patents when the query was shortened to search only within the abstract and title. A fewer number of patents, 17 , was obtained when the string was modified including additive manufacturing and medical devices. The search was further improved by using Boolean operators, as previously described, to include only innovations for medical devices, prosthesis, or orthoses in combination with additive manufacturing. From this search, 41 patents were retrieved. In total, 86 patents were found when the keyword "3D printing" was added to the previous entries, as shown in Table 1. Despite the constraint to medical devices, words related to the veterinary field were recurrent, and as they did not fit the scope of this paper, they were omitted, resulting in a more specific query (query 12 in Table 2).

This query excludes the terms for veterinary, animal, or pets and uses the proximity operator "wd2". This operator searches terms related to additive manufacturing or $3 \mathrm{D}$ printing with a proximity of two words 


\section{Figure 1. Technology-based Search} Query Results

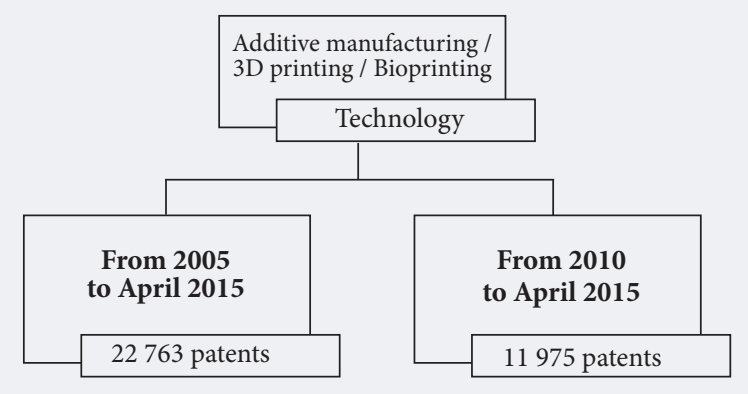

Note: This and the following two figures demonstrate patent search results from 2005-01-01 to 2015-04-15 and 2010-01-01 to 2015-04-15 Source: composed by the authors.
Figure 2. Technology and Medical Approach-based Search Query Results

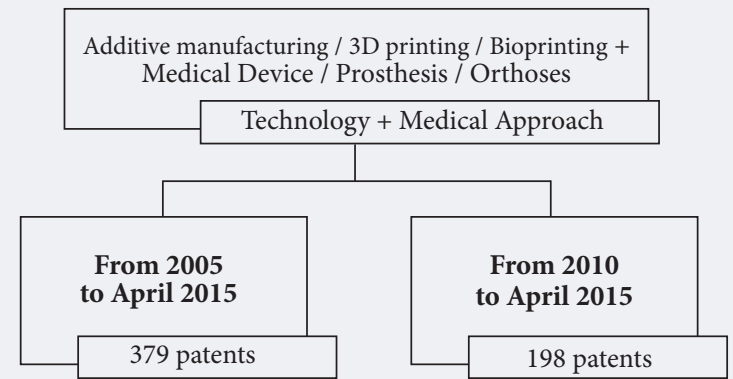

Source: composed by the authors

from the terms for medical devices. This query produced 115 patents over the period stated (2005-01-01 to 2015-04-15), with only nine patents published by 2005, and a higher number of patents, 20 , published in 2014. This search did not produce results for the partial year of 2015 (through 2015-04-15).

More related terms were gradually added to the preliminary queries and the search periods were also modified. A total of 15,521 patents were obtained from 2005-01-01 to 2015- 04-15 when the search was carried out with Query 6, focused on a general search for additive manufacturing. Query 7, also for additive manufacturing, included more terms related to this technology, and two periods were defined, 2005-01-01 to 2015-04-15 and 2010-01-01 to 2015-04-15. This query yielded 22,763 patents from 200501-01 to 2015-04-15, and 11,975 patents from 2010-01-01 to 2015-04-15, as shown in Figure 1.

Query 8 encompassed terms related to technology and "medical application" for the previously defined periods. This query resulted in 379 patents from 2005-01-01 to 2015-04-15 and 198 patents were found from 2010 to 2015-04-15, shown in Figure 2.

The next step consisted of the inclusion of terms related to materials. The search string identified as Query 9 , incorporates the terms polym ${ }^{\star}$ and is an example of the queries that encompass the terms for each of the materials listed in Table 3. This string yielded only 24 patents from 2005-01-01 to 2015-04-15 and 17 from 2010-01-01 to 2015-04-15, as shown in Figure 3.

As previously mentioned, the main medical applications for AM were determined to be dental, vascular graft, and tendon prostheses, therefore specific analyses were developed for them. Each of these terms was combined with the keywords for the materials listed in Table 3 . The same period was defined for the searches, 2005-01-01 to 2015-04-15. In total, 120 searches were performed using these combinations of terms, obtaining a total of 1,479 patents. They were analyzed and those not related to the topic were eliminated. The final set of documents obtained was as follows: 126 patents focused on AM for dental applications, 108 for tendon replacement, and 23 for vascular grafts.

Figure 3. Technology, Medical Applications, and Material-based Search Query Results

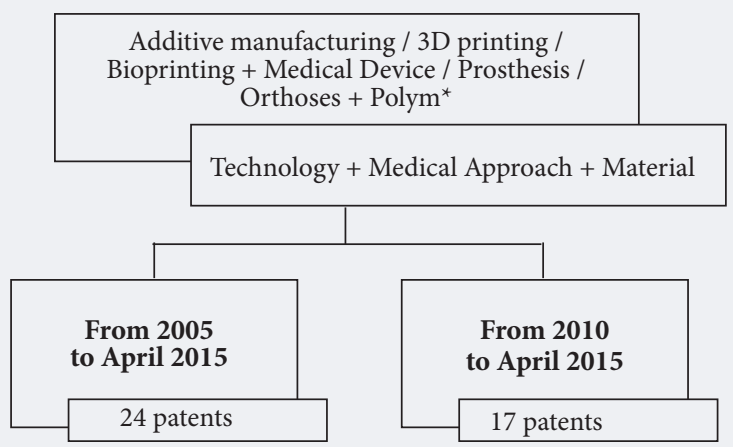

Source: composed by the authors.
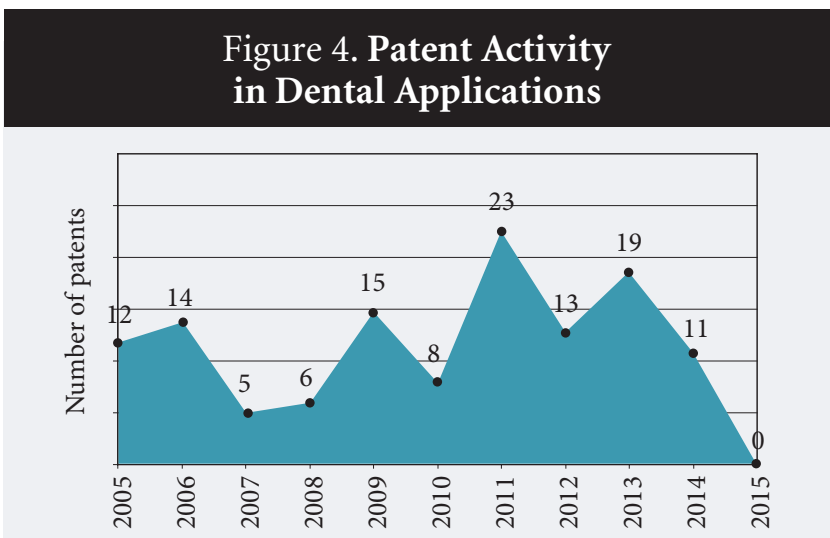

Note: This and the following two figures demonstrate patent search results from 2005-01-01 to 2015-04-15

Source: composed by the authors. 
The area with the most patent activity for the ten-year period was found to be the dental industry with 126 patents. A patent analysis was performed to identify the most frequently used materials. The analysis showed a total of 23 different materials; the top 15 are listed in Table 3. Only four of them were present in more than ten patents. Ceramics, found in 24 patents, was the most commonly used material for dental applications, followed by titanium, found in 20 patents, wax, used in 16 patents, and plastic, found in 12 patents. Figure 4 shows the patent activity in dental applications per year for the period from 200501-01 to 2015-04-15. Although this was the industry with the most activity, it does not have a uniform trend. To determine the patent average per year, the search period was divided in two, from 2005 to 2010 (previously to 2011, which is the year with the maximum number of patents, 23), and from 2012 to 2014. The results showed an average of 10 patents per year from 2005 to 2010, while the for the period from 2012 to 2014 the average was 14.3 patents per year.

After dental applications, tendon prostheses were the following most patented innovation, with a total of 108. These patents employed a higher number of materials: 34 . Table 4 lists the 15 most popular, where it can be observed that polyethylene was the most used material, contained in 46 patents; followed by plastic present in 37 patents and polypropylene, which was used in 20 patents. Tendon applications demonstrated steady patent activity between 2005 and 2014, as shown in Figure 5. The patent average per year was also determined for two periods. Before 2012, the year with most patents (24), the average was 8.8 , while for 2013 to 2014 , the average was 11.5 . Finally, no patent activity was registered in 2015 up to 2015-04-15, when the search concluded.

Third place in AM patenting activity was occupied by vascular graft applications, with 23 patents, which employed a total of 32 different materials. Table 5 lists the top 15 materials, with only three found in more than five patents. Polyethylene was the most used material, present in 10 patents, followed by plastic (in general) in 8 patents, and finally furan in 6 patents. Figure 6 outlines the patent activity per year over the period from 2005 to the partial year of 2015, which reached a peak in 2006 with 6 patents. Vascular graft applications had an average of 2.3 patents per year.

A comparison between dental, tendon, and vascular graft applications can be observed in Figure 7 . They reached their peak in 2011,2012, and 2006, respectively. The highest average number of patents per year was found for dental applications, with 12.6 patents per year, followed by tendon applications with 10.8, and vascular with only 2.3 patents per year.

Regarding materials, plastics were found to be the most widely used material. Polyethylene represents $13 \%$ of the materials registered for tendon applications, $11 \%$ for vascular graft applications, and only $2.5 \%$ of the materials for dental applications. On the other hand, ceramic materials were used most in dental applications, being the prevalent material in $20 \%$ of dental patents, $4 \%$ of those for tendon applications, and just $1 \%$ for vascular graft applications. Metals are not as widely used as plastics in AM for the

\section{Table 3. Additive Manufacturing Top Materials for Dental Applications}

\begin{tabular}{|l|c|}
\hline \multicolumn{1}{|c|}{ Material } & Patent Frequency \\
\hline Ceramics & 24 \\
\hline Titanium & 20 \\
\hline Wax & 16 \\
\hline Plastic & 12 \\
\hline Steel & 9 \\
\hline Nickel & 5 \\
\hline PEEK & 5 \\
\hline Stainless Steel & 4 \\
\hline Thermoplastic & 4 \\
\hline Polyethylene & 3 \\
\hline Silver & 2 \\
\hline Alkyd & 1 \\
\hline Epoxy & 1 \\
\hline Melamine & 1 \\
\hline Nylon & 1 \\
\hline Source: composed by the authors. \\
\hline
\end{tabular}

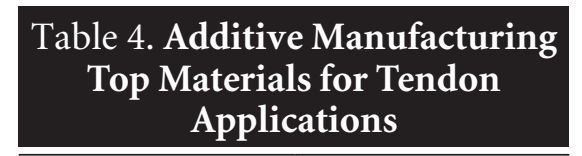

\begin{tabular}{|l|c|}
\hline \multicolumn{1}{|c|}{ Material } & Patent Frequency \\
\hline Polyethylene & 46 \\
\hline Plastic & 37 \\
\hline Polypropylene & 20 \\
\hline Wax & 18 \\
\hline Polylactic acid & 17 \\
\hline Ceramic & 16 \\
\hline Polyamide & 16 \\
\hline Titanium & 15 \\
\hline Steel & 14 \\
\hline Thermoplastic & 14 \\
\hline Furan & 12 \\
\hline Nylon & 11 \\
\hline Clay & 10 \\
\hline Paper & 10 \\
\hline Polyvinyl chloride & 10 \\
\hline Source: composed by the authors. \\
\hline
\end{tabular}

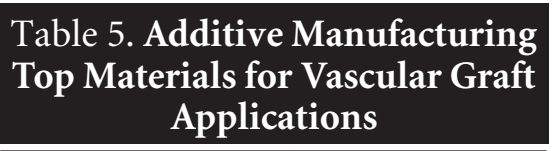

\begin{tabular}{|l|c|}
\hline \multicolumn{1}{|c|}{ Material } & Patent Frequency \\
\hline Polyethylene & 10 \\
\hline Plastic & 8 \\
\hline Furan & 6 \\
\hline Nylon & 4 \\
\hline Polyamide & 4 \\
\hline Polylactic acid & 4 \\
\hline Polypropylene & 4 \\
\hline Wax & 4 \\
\hline Clay & 3 \\
\hline Epoxy & 3 \\
\hline Paper & 3 \\
\hline Polycarbonate & 3 \\
\hline Polyolefin & 3 \\
\hline Silver & 3 \\
\hline Melamine & 2 \\
\hline Methacrylic & 2 \\
\hline Source: composed by the authors. \\
\hline
\end{tabular}


Figure 5. Patents in Tendon Applications

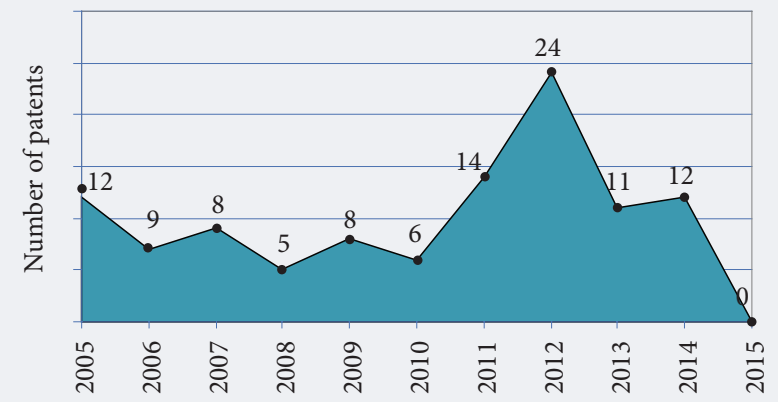

Source: composed by the authors.

\section{Figure 6. Patents in Vascular Grafts Applications}

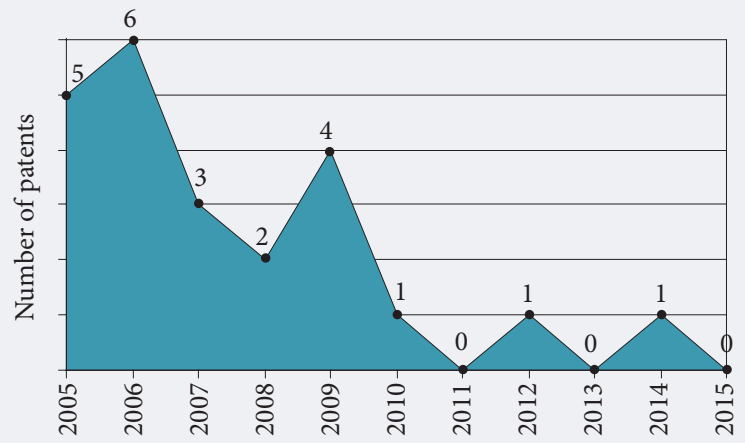

Source: composed by the authors.

healthcare sector, however, titanium represents the second most used material for dental applications, with use in $17 \%$ of the patents. This metal also represents $4 \%$ of materials in tendon applications, and $2 \%$ of the metals used in vascular graft developments. The second most used metal was found to be stainless steel, representing 3\% for dental applications, $3 \%$ of the materials in tendon applications, and $2 \%$ of the materials for vascular grafts.

\section{Conclusion}

The identification of the main global applications of additive manufacturing in the healthcare sector and the most used materials was conducted in this paper. The authors employed a patent analysis combined with an expert assessment. This methodology can be used across a wide range of disciplines. Although studies have been developed to identify global trends and the main actors using AM technology, there is still not enough discussion about patent activity for AM's main applications and materials in the healthcare industry, which makes such a study relevant for strategic R\&D planning.

In this research, three main medical applications of AM were identified: dental implants, vascular grafts, and tendon replacement. Over the analyzed period, small variations in the frequency of patent activity per year were observed. Despite this, the increase on average of patents per year was observed from 2011 to 2014 for dental and tendon applications.

The obtained results were consistent with what has been reported on the use of materials [Wohlers et al., 2016], which demonstrates the predominant use of plastics over metals. The use of metals has been found to be limited, with titanium and stainless steel among the most frequently employed metals. The majority of the medical devices such as jaw implants, hip, knee, and shoulder prostheses are mainly comprised of these metals, which are difficult to use in tailored manufacturing carried out by traditional

\section{Figure 7. Patent Activity for Dental, Tendon, and Vascular Graft Applications}

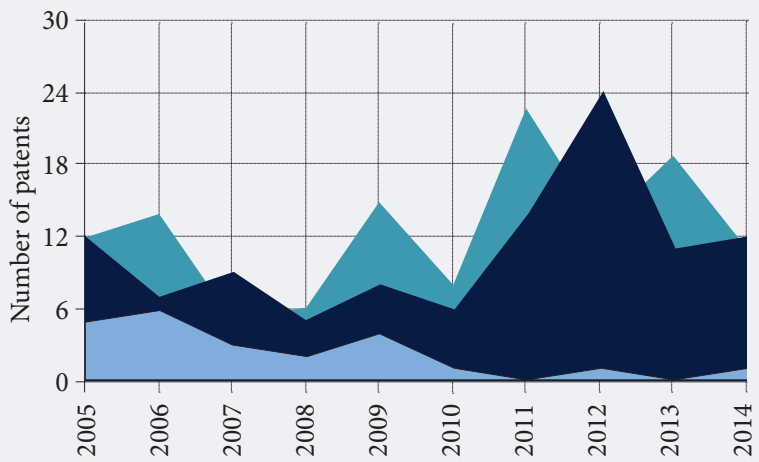

Vascular Graft Applications

Tendon Applications

Dental Applications

Note: The figure demonstrates patent search results from 2005-01-01 to 2014-12-31 Source: composed by the authors. 
methods, which results in extremely expensive end products. This offers an opportunity for innovation in the development of such products using AM, where the overall cost and the manufacturing time could be substantially reduced.

The development of the search query involved an extensive manual iterative process to test the information collected and it required validation by experts. An automatic method could be developed to carry out this process, thus reducing the time to perform the high number of searches.

This methodology was successfully applied for the identification of the main applications of and materials used by AM technology in the healthcare sector, but it can be implemented to identify potential research opportunities across a wide range of disciplines.

This work was funded by Tecnologico de Monterrey through the Escuela de Ingenieria y Ciencias, and it was also supported by a postdoctoral scholarship granted by the Mexican National Council for Science and Technology (CONACYT). The funders had no role in the study design, data collection and analysis, decision to publish, or preparation of this manuscript.

\section{References}

Abercrombie R.K., Udoeyop A.W., Schlicher B.G. (2012) A study of scientometric methods to identify emerging technologies via modelling of milestones. Scientometrics, vol. 91, no 2, pp. 327-342. DOI:10.1007/s11192-0110614-4.

Álvarez K., Nakajima H. (2009) Metallic scaffolds for bone regeneration. Materials, vol. 2, no 3, pp. 790-832. DOI:10.3390/ma2030790.

Archibugi D., Pianta M. (1996) Measuring technological change through patents and innovation surveys. Technovation, vol. 16, no 9, pp. 451-468. DOI:10.1016/0166-4972(96)00031-4.

Attar R., Fraenkel A.S. (1997) Local feedback in full-text retrieval systems. Journal of the Association for Computing Machinery, vol. 24, no 3, pp. 397-417.

Altuntas S., Dereli T., Kusiak A. (2015) Forecasting technology success based on patent data. Technological Forecasting and Social Change, vol. 96, pp. 202-214.

Banks J. (2013) Adding Value in Additive Manufacturing. IEEE Pulse, vol. 4, no 6, pp. 22-26. DOI:10.1109/ mpul.2013.2279617.

Bonino D., Ciaramella A., Corno F. (2010) Review of the state-of-the-art in patent information and forthcoming evolutions in intelligent patent informatics. World Patent Information, vol. 32, no 1, pp. 30-38. DOI:10.1016/j. wpi.2009.05.008.

Chang S.W.C, Trappey C.V., Trappey A.J.C., Wu S.C. (2014) Forecasting dental implant technologies using patent analysis. Paper presented at the Portland International Conference on Management of Engineering \& Technology (PICMET 2014), 27-31 July 2014, Kanazawa, Japan.

Dehghani M., Dangelico R.M. (2017) Smart wearable technologies: Current status and market orientation through a patent analysis. Paper presented at the IEEE International Conference on Industrial Technology (ICIT 2017), 22-25 March 2017, Toronto, ON, Canada.

Fabry B., Ernst H., Langholz J., Köster M. (2006) Patent portfolio analysis as a useful tool for identifying R\&D and business opportunities-an empirical application in the nutrition and health industry. World Patent Information, vol. 28, no 3, pp. 215-225. DOI:10.1016/j.wpi.2005.10.004.

Fujii A. (2007) Enhancing patent retrieval by citation analysis. Proceedings of the 30th Annual International ACM SIGIR Conference on Research and Development in Information Retrieval (SIGIR '07), New York: ACM, pp. $793-$ 794.

Hornick J. (2016) 3D Printing in Healthcare. Journal of 3D Printing in Medicine, vol. 1, no 1, pp. 13-17.

Okamoto M., Shan Z., Orihara R. (2017) Applying Information Extraction for Patent Structure Analysis. Proceedings of the 40th International ACM SIGIR Conference on Research and Development in Information Retrieval (SIGIR '17), New York: ACM, pp. 989-992. DOI: 10.1145/3077136.3080698.

Rodríguez M., Cruz P., Avila A., Olivares E., Arellano B. (2014) Strategic Foresight: Determining Patent Trends in Additive Manufacturing. Journal of Intelligence Studies in Business, vol. 4, no 3, pp. 42-62.

Schubert C., van Langeveld M.C., Donoso L.A. (2014) Innovations in 3D printing: A 3D overview from optics to organs. The British Journal of Ophthalmology, vol. 98, no 2, pp. 159-161. DOI:10.1136/bjophthalmol-2013-304446.

Trappey A.J.C., Tung J.T.C., Trappey C., Wang T.M., Tang M.Y.L. (2015) Computer supported ontology-based patent analysis considering business processes and strategic patent portfolio management. Proceedings of the 19th IEEE International Conference on Computer Supported Cooperative Work in Design (CSCWD), Calabria, 2015 (eds. G.Fortino, W.Shen, J.-P. Barthès, J. Luo, W. Li, S. Ochoa, M.-H. Abel, A. Guerrieri, M. Ramos), Danvers, MA: IEEE, pp. 528-533. DOI: 10.1109/CSCWD.2015.7231015.

Ventola C.L. (2014) Medical Applications for 3D Printing: Current and Projected Uses. PঊT: A Peer-reviewed Journal for Formulary Management, vol. 39, no 10, pp. 704-711. DOI:10.1016/j.infsof.2008.09.005.

Wohlers T.T., Campbell R.I., Caffrey T. (2016) Wohlers Report 2016: 3D Printing and Additive Manufacturing State of the Industry: Annual Worldwide Progress Report, OakRidge, CO: Wohlers Associates.

Zhang L., Li L., Li T. (2015) Patent Mining: A Survey. SIGKDD Explorations Newsletter, vol. 16, no 2 (May 2015), pp. 1 -19. DOI=http://dx.doi.org/10.1145/2783702.2783704. 